\title{
Risk Factors for Development of Children with Down Syndrome in Brazil
}

\author{
Wesley Correa*, Maria de Fatima Minetto, Rafaeli Cappellaro-Kobren, \\ Josafá Moreira Cunha
}

School of Education, Universidade Federal do Paraná, Curitiba, Brazil

Email: *wesleycorrea.psicologo@gmail.com

Received 13 May 2015; accepted 5 July 2015; published 8 July 2015

Copyright (C) 2015 by authors and Scientific Research Publishing Inc.

This work is licensed under the Creative Commons Attribution International License (CC BY).

http://creativecommons.org/licenses/by/4.0/

c) (i) Open Access

\begin{abstract}
The study of risk factors that affect the development of children with Down syndrome (DS) has been the main subject of several studies. In the Brazilian context, the development of instruments to identify such risks is still a challenge. The current study had the objective of examining the characteristics of a diagnostic organizer instrument which detects risk factors for development. The study was conducted in a clinic that offers services to children with DS in a Public Hospital in Curitiba, Brazil-and 15 parents of children from 0 - 8 years with DS that use the ambulatory service were interviewed, while the children's medical records were also consulted. With the use of the Organization Diagnostic for Early Intervention (ODAP (GAT, 2008)), current and past conditions of child development as well as risk factors were evaluated. The research provided an organization of diagnostic, identifying cumulative risks factors for child development with emphasis on biological and environmental factors, and revealed vulnerabilities. The study provided a comprehensive understanding about the influence of the risk factors to development, as well as informing the development of strategies for intervention to enhance protective factors and promote positive child development and higher quality in family and social relationships.
\end{abstract}

\section{Keywords}

Risk Factors, Child Development, Down Syndrome

\section{Introduction}

The Ministry of Health in Brazil emphasizes attention on child development since the 80s, articulating actions and projects that not only provide the basic health care for the Brazilian population, but also offer special attention to

"Corresponding author.

How to cite this paper: Correa, W., Minetto, M. F., Cappellaro-Kobren, R., \& Cunha, J. M. (2015). Risk Factors for Development of Children with Down Syndrome in Brazil. Creative Education, 6, 1285-1293.

http://dx.doi.org/10.4236/ce.2015.612128 
neonatal monitoring, especially among those that are at risk (Brazil, 2012). Public policies encourage family care programs, with actions linked to the integral protection and development of children, family relations, and education, considering that this stage in development is crucial in a healthy development, especially when children are faced with hazardous or vulnerable conditions (Soejima \& Bolsanello, 2012; Minetto e Bolsanello, 2012; Bolsanello, 2012).

Poletto and Koller (2008) point out that the interpretation of social relations is fundamental to understanding healthy human development, proposing the approach to such questions through a theory dedicated to the interaction of individuals in their diverse contexts. The Bioecological Theory, proposed by Bronfenbrenner (1996/ 2011), emphasizes the concept of human development across the life cycle, criticizing studies on child development that limit their analytical approach to individual factors and disregard the multiple influences on such process. The bioecological model consists in four multidirectional aspects that are interconnected including the developing Person, Process, Context and Time (PPCT).

Bronfenbrenner and Morris (1998), Bronfenbrenner (1996, 2011), when referring to the Person, include the personal characteristics, convictions, temperament, motivations and values. The process involves the active participation in progressive, complex and reciprocal interaction with people, objects and symbols in the immediate environment. When the authors refer to the context, they also include an environmental set in which the person is inserted and where the entire development process happens. These environments are named as microsystem, mesosystem, exosystem and macrosystems. These include respectively both the immediate context for the person, as well as the farthest which, although not in direct contact with the person influences development. Moreover, the author considers the relevance of understanding Time, in the sense of historical changes that affect development.

Departing from any ecological environment where interactions may happen, prioritizing the development of research with respect to children and the environment in which it is involved, this model emphasizes the importance of the context to understand the processes in which individuals are involved throughout development, and it is important to identify risk and protective factors, especially in childhood.

Hanson and Lynch (1989) conceptualize three categories of risk situation which may influence child development negatively: risk factors of a biological order (related to pre, peri and postnatal periods, such as infections, birth conditions, mother's health); established (genetic based factors); and environmental (factors related to family, social and institutional environments).

Children with Down syndrome (DS) have established risk, or actual problems, since they present mainly genetic alterations. According to Person and colleagues (2013), the US has about 250,000 people with Down syndrome, representing 1 in 830 live births. According to the authors, among the main aspects inherent to DS, it highlights the chromosomal changes identified by trisomy 21; medical problems and cognitive skill that vary greatly from one person to another, mild and moderate intellectual disabilities, heart problems, among others. In Brazil the Down Movement (2012) reports the birth of a child with DS in every 700 live births.

Henn, Piccinini and Garcias (2008) consider that the coming of a child in the family, creates besides a great expectation, determined by the environmental changes. Thus, the arrival of a child with Down Syndrome in this context requires certain adjustments within the family, as this child has comorbidities typical of the syndrome, which may correspond to unfavorable developmental limitations, needs more stimulation in their potential to strengthen their capabilities. In this process, a larger commitment of time and resources are demanded in comparison to children without such developmental delays.

Portes, Vieira, Crepaldi, More and Motta (2013) wrote a literature review discussing aspects of DS and their impact on the progress of the family system, agreeing with Broffenbrenner's theory. Concerning the results, the authors found that "the potential risk or protective factors are directly related to the environmental and developmental conditions in which the child is integrated. Moreover, one should consider that those with DS have a rhythm that may or may not be deficient” (Portes et al., 2013: p. 459).

The Brazilian population faces many socio-political and cultural adversities which influence the development, learning and schooling (Mantoan, 2012; Oliveira, 2011; Minetto, 2008). The child with DS who already has changes of genetic order, may be exposed to cumulative risks to development, involving environmental and biological aspects. In times of inclusion and through a bio-ecological perspective, considering diversity is essential to understanding the developing person is, especially in regard to potential risks to development. According to Krebs $(2005,2006)$ the respect to the individuality and an expanded view of the development are essential in order to establish effective practices for inclusion in education. 
In Brazil, several instruments are used to identify potential risk factors, such as the Denver Development Screening Test-Denver II (Frankenburg et al., 1990) and the Interview Guide for Biopsychosocial Risk (Santa Maria-Mengel, 2007). However no organizer of different diagnostics, based on international classifications, is available in Brazil to support the multiple professionals engaged in interventions to promote the developments of children, especially those exposed to cumulative risks. In the face of such challenge an instrument that had its foundations connected to WHO, CIF, DSM-5, ICD-10, which also enabled the screening of several aspects including biological and environmental conditions in order to verify their influence in the area of health and education. The objective of this study was to investigate the viability of using a diagnostic organizer instrument that detects risk factors for development among Brazilian children.

\section{Method}

This research uses a quantitative approach, with an exploratory and descriptive method. The method consisted of a survey carried out at the Ambulatory of Down Syndrome of a Public Hospital in Curitiba, Brazil. Study participants were 15 families of children with DS from 0 to 8 years old who received services from the interdisciplinary team in this clinic, and the data collection occurred through the analysis of their medical files and interviews with the parents. From a total of 7 children, 7 were aged between 0 and 24 months, 5 aged between 24 and 48 months, and 3 above 48 months; in relation to children's gender, 9 are girls and 6 are boys; there was a higher prevalence of questionnaires answered by mothers (73\%); and a higher concentration of fathers aged more than 40 years and, for mothers, the most frequent age group was between 20 and 30 years; marital status of the parents of the children surveyed showed that $53.33 \%$ are married, $33.33 \%$ are separated/divorced, and $13.33 \%$ are cohabiting; the parents' educational level showed that $46 \%$ have Complete High School, $20 \%$ with incomplete primary education, $17 \%$ with elementary education, Complete and Incomplete higher education both featuring 7\%, while 3\% have abandoned High School; the income of families with the highest concentration being BRA 1000.00 and BRA 2000.00, with fewer families with income above BRA 3000 in which the values were computed based on the Brazilian minimum wage in the period of research (BRA 724.00).

The protocol of Diagnostic Organization of Early Intervention (ODAP (GAT, 2008)) was used, following international parameters in health and development based in the "Libro Blanco de La AtenciónTemprana" [White Book of Early Intervention] (Madrid, 2005), structured in the Early Intervention (EI) meetings developed during five years by the GAP's interdisciplinary team. Among the principles that guided the work of the GAP in this process, it is relevant to highlight: the design of research strategies, promoting preventive and protective actions, as well as to establish a universal language among professionals involved in EI. The instrument offers possibilities to unify the diagnostic criteria, contributing to the classification of the disorders of child development. The instrument also intended to gather epidemiological information about children with DS in Brazil.

This instrument has a multifactorial structure divided in three levels: a) risk factors for developmental disorders in three contexts (biological, familial and environmental), b) dysfunctions or disorders that can be diagnosed in the child in the course of the relationship with the family and the characteristics found in the environment where the child is inserted, c) six coordinates of the first two levels, presented in 27 categories and 195 diagnostic elements; giving expanded interpretation with regard to diagnostic organization objectively looking "to describe the different levels of intervention, and enables statistical research from which the necessary resources can be planned” (ODAP (GAT, 2008: p. 28)).

\section{Results}

The results of the ODAP (GAT, 2008) showed that the majority of the participants has at least one biological risk factor, in which $80 \%$ of respondents had prenatal problems, $66.7 \%$ with problems in the perinatal period, with $60 \%$ problems in the postnatal period. Moreover, all children in this sample exhibited diagnostics of biological risk in relation to the domain assessed in Coordinate I of ODAP (GAT, 2008).

In regard to Biological Risk Factors (Coordinate I), in the sub-item of Prenatal family histories of Hearing, Visual, Neurological and Psychiatric possible recurrence were verified $(n=5)$; teratogenic agents (environmental, $\mathrm{n}=2$ and derived from diseases, $\mathrm{n}=5$ ) Malformations (from CNS-central nervous system, Congenital Hydrocephaly, $\mathrm{n}=1$; that affect other organs; congenital heart defects, gastrointestinal, genital, urinary tract, dysgenesis of extremities, $n=5)$; Situations that caused problems during pregnancy $(n=2)$ For the perinatal subsection, lower weight was highlighted (2500 grams, $n=6$; and 1500 grams, $n=1)$; gestational age ( $<37$ weeks, 
$\mathrm{n}=6$; $<32$ weeks, $\mathrm{n}=1$ ); Newborn with Apgar scores $<3$ at 1 st minute or $<7$ at 5 th minute $(\mathrm{n}=1)$; newborn with mechanical ventilation for more than 24 hours $(n=4)$; Newborn with neonatal respiratory insufficiency and other disorders $(n=3)$; Newborn with hyperbilirubinemia requiring blood transfusion $(n=4)$; Neonatal spasms $(n=1)$; Neurological dysfunction $(n=1)$; meningitis or neonatal encephalitis $(n=1)$. In the postnatal subsection postnatal infections of the central nervous system were verified $(n=2)$; Chronic developmental diseases $(n=2)$; Epilepsy ( $\mathrm{n}=1)$; Developmental delays in weight and height gains $(\mathrm{n}=8)$; and chronic endocrine and metabolic changes $(n=1)$. For the subsection of Other Biological Factors all children showed warning signs detected by health professionals from the Network of Primary or Secondary Health Care, or education professionals; and warning signs detected in babies for whom data is unknown $(\mathrm{n}=10)$.

In Table 1 it can be seen that most of the participants have family risk factors (Coordinate II) and represent $80 \%$ in subitem Parental Characteristics and $93.3 \%$ of postnatal period. This may suggest a relation to the problems in the postnatal period with some sort of weakness in the health of parents who can cause a decrease in the quality of care dedicated to the children. It also highlights the subsection of stress during pregnancy with only $13.3 \%$, a relatively low response frequency.

Regarding the Family Risk Factors (Coordinate II), in subsection Parental characteristics, they were found more frequently among parents aged less than 20 years or greater than $40(n=10)$; parents with addictions $(n=$ 1 ); and physical, neurological diseases $(n=3)$. Regarding the family characteristics of this sub-item, there was evidence of familiar rupture and/or critical situations $(n=6)$; Seriously altered family environments $(n=5)$; Background and situations of physical or psychological abuse $(n=2)$; Family (socially excluded, $n=1$, single parent, $n=4)$; and presence in the household of people with severe diseases or disorders $(n=1)$. In subsection Stress in Neonatal Period was found perinatal diagnosis of probable physical or mental disability or somatic malformation $(\mathrm{n}=4)$. The sub-item postnatal period showed postnatal diagnosis of probable or mental disability, serious illness or somatic malformation $(n=11)$; Situations of physical or psychological abuse $(n=1)$; Family breakdown and critical situations $(n=4)$; Maternal postpartum depression $(n=1)$; Babies with frequent hospitalization ( $\mathrm{n}=1)$; and continuous caretakers change $(\mathrm{n}=1)$.

The risk of Environmental Factors (Coordinate III), demonstrated exposure to Social Environments with stress factors and exposure to the Family Social Exclusion factors, with the same relative frequency response, $40 \%$ and $60 \%$. But this proportion is merely a coincidence since the answers to both variables does not necessarily represent the same families.

Table 1. Frequency of diagnostics—coordinate II: family risk factors.

\begin{tabular}{ccc}
\hline Variable/Response & Absolute Frequency & Relative Frequency (\%) \\
\hline Parental characteristics & 12 & 80 \\
Yes & 3 & 20 \\
No & & \\
Family characteristics & 7 & 46.67 \\
Yes & 8 & 53.33 \\
No & & \\
Stress during pregnancy & 2 & 13.33 \\
Yes & 13 & 86.67 \\
No & & 20 \\
Neonatal stress & 3 & 80 \\
Yes & 12 & \\
No & & 93.33 \\
After birth & 14 & 6.67 \\
Yes & 1 & \\
No & &
\end{tabular}


Regarding the Environmental Risk Factors (Coordinate III), the sub-item of Exposure to Environmental Contexts with stress factors included prolonged hospitalization $(n=1)$; and frequent exposure to impaired sensory stimulation $(\mathrm{n}=2)$. In sub-item of Social Environments with stress factors demonstrated environments that were insecure and little conducive to the development of the child $(n=4)$; Exposure to unstable/inappropriate relationships ( $n=2)$; Exposure to violent scenes at home, in the institutions or on television $(n=3)$; and exposure to inappropriate practices situations $(\mathrm{n}=1)$. Regarding the sub-item of Exposure to factors of Family Social Exclusion, there were four cases found living under conditions which facilitate social isolation in their own familiar environment and in relation to other social environments; families with difficulties to access social resources (n $=5)$.

Table 2 shows that all of the participant children presented delays in development, developmental disorders (cognitive, communication and language), and other Disabilities, and this last sub item corresponds to DS, as this was the most frequent diagnostic in this sample. Note that this diagnostic category was absent in earlier items. The sub-items for Disorders (Visual, psychomotor, and adjustment and behavioral) did not exceed in any case a relative frequency of $20 \%$.

On Developmental Disorders (Coordinate IV), assessment was made for visual disorders (nystagmus, $\mathrm{n}=1$ ), psychomotor disorders (simple psychomotor delayed, $\mathrm{n}=2$ ) and regulation and behavioral disorders (Disorganized, with motor impulsivity, $\mathrm{n}=1$; attention deficit hyperactivity disorder, combined type, $\mathrm{n}=1$, attention deficit hyperactivity disorder, predominantly hyperactive-impulsive type, $n=1$ ). All children evaluated presented developmental disorders (Cognitive, Communication and Language), and these same children exhibited other disabilities. None of the participating children showed evidence of disorders in motor development, auditory, somatic expression, emotional and autism spectrum.

\begin{tabular}{|c|c|c|}
\hline Variable/Response & Absolute Frequency & Relative Frequency (\%) \\
\hline \multicolumn{3}{|l|}{ Visual disorders } \\
\hline Yes & 1 & 6.67 \\
\hline No & 14 & 93.33 \\
\hline \multicolumn{3}{|l|}{ Psychomotor Disorders } \\
\hline Yes & 2 & 13.33 \\
\hline No & 13 & 86.67 \\
\hline \multicolumn{3}{|l|}{ Delayed development } \\
\hline Yes & 15 & 100 \\
\hline No & 0 & 0 \\
\hline \multicolumn{3}{|c|}{ Cognitive Development Disorders } \\
\hline Yes & 15 & 100 \\
\hline No & 0 & 0 \\
\hline \multicolumn{3}{|c|}{$\begin{array}{l}\text { Communication and Language } \\
\text { Development Disorders }\end{array}$} \\
\hline Yes & 15 & 100 \\
\hline No & 0 & 0 \\
\hline \multicolumn{3}{|c|}{ Regulation and behavioral disorders } \\
\hline Yes & 14 & 93.33 \\
\hline No & 1 & 6.67 \\
\hline \multicolumn{3}{|l|}{ Other disabilities } \\
\hline Yes & 15 & 100 \\
\hline No & 0 & 0 \\
\hline
\end{tabular}


The data related to the Family (Coordinate V), in its majority presented issues in family-children relationship (80\%), including overprotection ( $(n=6)$, tendency to apathy or neglect $(n=1)$, rejection $(n=1)$, aggressive-dominant tendencies $(n=2)$, and ambivalent tendencies $(n=1)$. There were also cases that showed disorders in interactions, with $40 \%$ of the responses (unstable, $n=1$; changes $n=3$; spoiled, $n=2$; and negligence, $n=1$ ).

For the data related to the Environment (Coordinate VI), were found in most of participant families (60\%). These included the absence of the caregivers $(n=2)$, maltreatment and abuse $(n=1)$, negligence $(n=3)$, excessive time in schools or early childhood centers $(n=1)$, lack of privacy $(n=3)$; slum formation $(n=1)$, violence and insecurity in the environment $(n=4)$, discrimination $(n=4)$ and a conjunction of factors of exclusion $(n=$ 2).

\section{Discussion}

Among the caregivers who participated in the research, the higher involvement of female caregivers was notorious, with a superior concentration of mothers in the services offered at the clinic. This corroborates the literature in which the participation of mothers and female caregivers is often more frequent in studies related to managing the care of children with special needs (e.g., Sousa et al., 2009). The mother has a crucial function in child development, such as the insertion of children in their social relations. To the extent that the child grows and develops, changes also occur in the environment, in the case of children with Down syndrome who often require special services and more dedication from the caregivers in order to fully develop (Andrade et al., 2012).

In regard to the age of the caregivers, the results presented here showed a high concentration of parents with more than 40 years and mothers aged between 20 and 30 years. The literature indicates that pregnancy in advanced ages (especially maternal age) is an important risk factor for the occurrence of the genetic disorder connected the syndrome in question. Trentin and Santos (2013), Brandão (2012) and Sobrinho (2010), provide a description of the extent to which women age their gametes and follow this process by providing a higher risk for episodes of fetal malformation and chromosomal disorders, pointing out that women aged under 30 have a higher incidence of children with Down syndrome, since there is a higher frequency of pregnancies during this period of life of women.

Related data indicates that $53.3 \%$ of respondent parents are married. According to Souza and Fiamenghi (2011), in a literature review, research found a lower level of divorce among parents of children with Down syndrome in comparison to parents in families with children without disabilities.

The results indicate that all children in the sample have actual problems, related to the DS. As Carvalho (2008) relates, the actual problems of physical limitations associated with delays in development occurs in chromosome anomalies. Every children in this sample also showed risk factors of a biological order, related to the first moments of a child's life (prenatal, perinatal and postnatal periods) and history of illnesses related to their parents were more frequently related during the prenatal period, corresponding to $80 \%$ of respondents. In this sense, Velasco et al. (2011) stress that human beings are vulnerable and dependent from the moment of birth, and that development is accomplished through the continuous interaction between the organism and the environment in which parental behavior influences the emerging powers of the cognitive children in linguistic, social and emotional levels, influencing child development.

An important fact displayed in the results is related to family risk factors, involving parental stress $(80 \%)$ and other risk factors in the post-natal period (93.3\%). The literature highlights how specific interpersonal characteristics of parents as potential risk factors, which may directly affect child development, including depression, parenting practices, literacy and educational levels, social interactions, the marital relationship, among others (Lamb \& Billings, 1997; Shapiro et al., 1998; Pereira-Silva \& Dessen, 2004, 2006; Cherubini, Bosa, \& Bandeira, 2008; Miranda et al., 2009; Minetto \& Crepaldi, 2010; Bridges et al., 2013).

In regard to the risk factors of an environmental order, the results indicate a $40 \%$ exposure to social environments with stress factors, while $60 \%$ of participant families were exposed to social exclusion factors. This corroborates Costa (2012), who discusses how the environmental risk factors are related to parental and community risk factors, as these are connected to poverty, isolation, and family disorganization, neglect by caregivers in the basic activities to provide the child, and the possible presence of psychiatric disorders.

Among the problems related to developmental disorders, there was a relevant point in the factors related to other disabilities, with $100 \%$ response for this item, which shows that all children have a disability, in this case the DS. The World Report on Disability (World Report on Disability, 2011), corroborating data from the World 
Health Organization (2011), add an estimate that over one billion people have at least one disability worldwide, representing a prevalence of $15 \%$ in the world population.

The family-related data showed greater convergence in the factors related to family-child interactions, comprehending $80 \%$ of the respondents, with a high tendency to overprotection. Müller and Jung (2010), PereiraSilva and Dessen (2004, 2006), Minetto and Crepaldi (2010) relate aspects of overprotection, pity or rejection from parents and guardians of children with disabilities, directly related to factors that are detrimental to child development, referring to the bond of these parents is with a particular syndrome, favoring the child is isolated and moving away more and more from the protective factors to development. It is relevant to add that Sobrinho (2010), in his literature review, identified in some research that mothers and parents of children with Down syndrome manifested depressive symptoms, obsessive, anxious, psychotic and neurotic traits, hostility, and somatization, being reflected negatively in the behavior of their children with the syndrome, including delinquent behaviors.

In the face of problems related to the environment, there was greater evidence within the environmental disorders subsection, including violence and insecurity, and also discrimination. Carvalho (2008) discusses how environmental factors have considerable importance in child development, related to vulnerabilities that can increase odds for negligent caregiving, which is in itself one of the most important environmental risk factors.

The ODAP (GAT, 2008) identified for this study the predominance of a family context with actual risk, since data shows a higher level of impairment in the forms of relationship family/child related to the overprotection in most cases, also presenting tendencies to overprotection, apathy and negligence, rejection, aggressive/dominant and negligence for the interaction disorders, showing instability in relations, altered family relations, deterioration in relations and negligent relations. Franco (2012) relates the management of activities dispensed to children with any special needs, the idealization of a child created from the imagination of parents even before the conception of a child. With the birth of the child, a break of the bond with this child may occur, as the child may be different from what parents desired, which ultimately influences the family relationship with the child, also affecting other contexts and increasing potential risks to child development.

The understanding of the results presented here can be interpreted in the light of a bioecological perspective and, such as Minetto and Crepaldi (2010) discuss the immediate microsystems in which the child participates urgently needs strategies to enhance the support network, and identify protective factors that children with cumulative risks may have, in order to promote a more harmonious development.

\section{Conclusion}

The study favorably discussed the process of identification of risk related to biological, familial and environmental factors. Situations of vulnerability, which may require further attention, can be usefully screened through the ODAP (GAT, 2008). It is worth noting that the sample here certainly has shown in many ways conditions that are favorable to development, but the purpose of this study was to highlight the potential risk factors for development.

With the diagnostic organization of the child, it was possible to understand the real dimension of developmental risks. The ODAP (GAT, 2008) proved to be a useful instrument to characterize the population in this sample of Brazilian children and families, as well as a facilitating the intervention of professionals involved in health and education, and shows itself as an important resource to target interventions promoting positive development. At the end of the application of this protocol, the professional has organized a comprehensive individual profile of each child. This can be useful, for example, in the context of early childhood education, by creating opportunities for the organization to receive the child and boost development, establishing organized protective factors in actions that support the family, while remaining aware of the vulnerability aspects.

Of course, this study is not without limitations, which include but are not limited to the sample size the location and participants. It used a very limited population due to the lack of knowledge about the instrument application viability and its scale. So we suggest that new studies be carried out with a larger population, to varying levels such as schools and health centers, and embrace a more differentiated population.

In the Spanish context ODAP (GAT, 2008) is used by professionals linked to child care and health care by identifying and organizing the real situation of risk to development. There has been a very distinct reality of Brazil, since most of the data was based on parental reports, and not in well documented profiles of the child. This fact should be better approached on future studies, since contaminations or inauthentic interpretations by 
the parents may have occurred.

The participation of professionals in filling out of this instrument is crucial to the reliability of the data, and the exchange of information, also providing a tool for dialogue among the interdisciplinary team involving health and education professionals involved in fostering protective strategies to child development.

\section{References}

Andrade, L. M. M., Vasconcelos, L. C., \& Branco, F. M. F. C. (2012). Experience of Mothers with Children with Down Syndrome. Interdisciplinary Journal Novafapi, 5, 21-25.

Brandão, I. M. (2012). Down Syndrome in Aracaju. Thesis, Aracaju: University Tiradentes.

Bolsanello, M. A. (2012). Presentation Dossier: Baby Education and Child Development: Intervention and Early Warning. Educating in Review (Printed), 1, 13-16.

Brazil Ministry of Health (2012). The Person Care Guidelines with Down Syndrome. Brasília: Ministry of Health.

Brazil Ministry of Health (2012). Child Health: Growth and Development. Brasília: Ministry of Health.

Bronfenbrenner, U. (M.A.V. Veronese, Trad.) (1996). Ecology of Human Development: Natural and Planned Experiments. Porto Alegre: Medical Arts. (Original Work Published in 1979)

Bronfenbrenner, U., \& Morris, P. A. (1998). The Ecology of Developmental Processes. In W. Damon, \& R. M. Lerner (Orgs.), Handbook of Child Psychology, Vol. 1: Theoretical Models of Human Development (pp. 993-1028). New York: John Wiley.

Bronfenbrenner, U. (A. Carvalho-Barreto, Trad.) (2011). Bioecology Human Development: Making the Most Humane Human Beings. Porto Alegre: Artmed. (Original Work Published in 2005)

Carvalho, E. C. (2008). Children at Risk. Porto: University Portucalense.

Cherubini, Z. A., Bosa, C. A.; Bandeira, D. (2008). Stress and Self-Concept in Parents of Children with Fragile X Syndrome. Psychology and Critical Reflection, 21, 409-417.

Costa, V. L. S. (2012). Early Intervention: An Exploratory Study on the Practice of a Disciplinary Team. Thesis, Lisbon: School of Education John of God.

Frankenburg, W. K., Dodds, J., Archer, P., Bresnick, B., Maschka, P., Edelman, N. et al. (1990) Denver II: Technical Manual and Training Manual. Denver, CO: Denver Developmental Materials.

GAT (2008). ODAT Descritivo Manual-Update 2008. Madrid: Royal Board on Disability.

Hanson, M. J., \& Lynch, E. W. (1989). Early Intervention: Implementing Child and Family Services for Infants and Toddlers Who Are At-Risk or Disabled. Austin, TX: PRO-ED.

Henn, C. G., Piccinini, C. A., \& Garcias, G. L. (2008). The Family in the Context of Down Syndrome: Reviewing the Literature. Study in Psychology, 13, 485-493.

Krebs, R. J. (2006). The Bioecological Theory of Human Development and the Context of Inclusive Education. Journal of Special Education, 1, 40-45.

Krebs, R. J. (2005). Inclusive Education and the Theory of Ecological Systems. In D. Rodrigues, R. Krebs, \& S. N. Freitas (Orgs.), Inclusive Education and Special Educational Needs (pp. 65-81). Santa Maria: UFSM.

Lamb, M. E., \& Billings, L. A. L. (1997). Fathers of Children with Special Needs. In M. E. Lamb (Org.), The Role of the Father in Child Development (pp. 179-190). New York: Wiley.

Minetto, M. F., \& Crepaldi, M. A. (2010). Educational Practices Parenting, Parental Beliefs, Parental Stress and Family Functioning of Parents of Children with Typical and Atypical Development. Ph.D. Thesis, Florianópolis: Federal University of Santa Catarina.

Minetto, M. F. (2008). The Curriculum in Inclusive Education: Understand the Challenge. Curitiba: IBPEX.

Minetto, M. F., \& Bolsanello, M. A. (2012). Sensorimotor Intelligence in Children with Down Syndrome. INFAD, 3, 129136.

Miranda, A., Grau, D., Rose, J., \& Meliá, A. (2009). Understanding Discipline in Families of Children with Attention-Deficit/ Hyperactivity Disorder: A Structural Equation Model. The Spanish Journal of Psychology, 12, 496-505. http://dx.doi.org/10.1017/S1138741600001876

Mantoan, M. T. E. (2012). The Challenge of Differences in Schools. Petrópolis: Publisher Voices.

Müller, D. C., \& Jung, S. I. (2010). The Impact on Maternal Psyche by the Birth of a Baby with Down Syndrome. Work Degree Completion, FACCAT.

Oliveira, J. B. G. (2011). The Perspective of People with Disabilities School Inclusion in Brazil: A Study of the Public Policy. Magazine Times and Spaces in Education, 6, 147-159. 
Person, A. P., Partyka, G., Jensen, M. K., Devine, O. J., Ramussem, S. A., \& McCabe, R. E. B. (2013). Current Estimate of Down Syndrome Population Prevalence in the USA. Journal of Pediatrics, 163, 1163-1168.

Pereira-Silva, N. L., \& Dessen, M. A. (2006). Families of Children with Down Syndrome: Feelings, Ways of Life and Parental Stress. Psychology Interaction, 10, 183-194.

Pereira-Silva, N. L., \& Dessen, M. A. (2004). What Does Having a Mental Disabled Child in the Family? Educating in Review, 23, 161-183.

Poletto, M., \& Koller, S. H. (2008). Ecological Contexts: Promoters Resilience, Risk and Protective Factors. Psychology Studies, 25, 405-416.

Portes, J. R. M., Vieira, M. L., Crepaldi, M. A., \& Motta, C. C. L. (2013). A Child with Down Syndrome: From the Perspective of Bio-Ecological Theory of Human Development, with Emphasis on Risk and Protective Factors. Boletim da Academia Paulista de Psicologia, 33, 446-464.

Santa Maria-Mengel, M. R. (2007). “Development Surveillance” Health Family Program: Screening to Identify Risks for Developmental Problems in Children. Doctorate Thesis, Ribeirão Preto: University of Sao Paulo.

Sobrinho, L. A. (2010). The Parental Care for Children with Down Syndrome under the Evolutionary Perspective. Thesis, Salvador: Federal University of Bahia.

Soejima, C. S., \& Bolsanello, M. A. (2012). Intervention Program and Early Intervention with Infants in Early Childhood Education. Educating in Review, 43, 65-79.

Sousa, J. I. G. S., Ribeiro, G. T. F., \& Melo, A. P. C. (2009). Down Syndrome: Feelings Experienced by Parents When Diagnosis. Pediatrics, 2, 100-108.

Souza, A. B., \& Fiamenghi Jr., G. A. J. (2011). The Relationship between Father and Son with Down Syndrome: A Literature Review. Graduate Notebooks in Developmental Disorders, 11, 23-27.

Trentin, F. E., \& Santos, V. L. P. (2013). General Aspects of Down Syndrome: A Biological Vision. Health School Notebooks, 1, 15-31.

Velasco, L. P. P., Martínez-Fuentes, M. T., Pérez-López, J., \& Díaz-Herrero, A. (2011). Mother-Infant Interaction and Infant Mental Development: Implications for Early Intervention. INFAD—Psychology Magazine, 1, 521-530.

World Health Organization; The World Bank (2011). World Report on Disability. Geneva: World Health Organization. www.who.int 